\title{
LA CUARTA GENERACIÓN DE DERECHOS HUMANOS
}

Joseph Malta. Universidad Nacional Autónoma de Honduras, Vicerrectoría Académica (VRA),

(Autor: Redactor).

E-mail: juan.malta@unah.edu.hn

Rutilia Calderón. Universidad Nacional Autónoma de Honduras, Vicerrectoría Académica (VRA),

(Co autora: lineamientos estratégicos).

E-mail rutilia.calderon@unah.edu.hn

Héctor Murcia. Miembro Grupo Gestor del Plan de Sostenibilidad en Derechos Humanos. VRA-UNAH.

(Co autor: revisor).

E-mail: hmurciap@yahoo.com.mx

\section{RESUMEN}

Este artículo es un aporte genuino, que llega a posicionar al problema de la pobreza y la exclusión social como motivo suficiente para imaginar otra forma y otra concepción de los derechos humanos: la cuarta generación. Confluyen la argumentación de la ciencia política inclusiva, la socioeconomía y el ecodesarrollo. Se fijan dos énfasis: los derechos de los pueblos y los derechos de la humanidad. La tolerancia, la inclusión y el ecodesarrollo es el fin último de la cuarta generación de los derechos humanos. Se deja en manos de los lectores una nueva teoría de derechos humanos y derecho al desarrollo. Los autores se auxilian de: John Locke, Bernardo Kliksberg y Enrique Leff.

\section{Palabras clave:}

Derecho a la Vida, Derechos Humano, Desarrollo Humano, Compromiso por el Desarrollo, Derecho al Desarrollo. 


\title{
4TH GENERATION OF HUMAN RIGHTS STATEMENTS
}

Vol. 4

Joseph Malta. Universidad Nacional Autónoma de Honduras, Vicerrectoría Académica (VRA), (Autor: Redactor).

E-mail: juan.malta@unah.edu.hn

Rutilia Calderón. Universidad Nacional Autónoma de Honduras, Vicerrectoría Académica (VRA), (Co autora: lineamientos estratégicos). E-mail rutilia.calderon@unah.edu.hn

Héctor Murcia. Miembro Grupo Gestor del Plan de Sostenibilidad en Derechos Humanos. VRA-UNAH.

(Co autor: revisor).

E-mail: hmurciap@yahoo.com.mx

\begin{abstract}
This article is a genuine contribution, reaching position to the problem of poverty and social exclusion as reason enough to imagine another way and another conception of human rights: the fourth generation. Converge the argumentation of the inclusive political science, Socioeconomics and eco-development. Two emphasis are set: the rights of peoples and the rights of mankind. Tolerance, inclusion and eco-development is the ultimate goal of the fourth generation of human rights. A new theory of human rights and right to development is left in the hands of readers. The authors help of: John Locke, Bernardo Kliksberg and Enrique Leff.
\end{abstract}

\section{Keywords:}

Right to life, human rights, human development, commitment to development, right to development. 


\section{A MANERA DE INTRODUCCIÓN: SUJETO COLECTIVO Y NATURALEZA INTEGRAL DE LOS DERECHOS HUMANOS}

Abrimos la puerta de entrada al tema vía la clasificación clásica y básica de los derechos humanos y procurar trascender hacia la suma de mayores argumentos que sirvan para construir y proponer un concepto de los derechos humanos que se ajuste a la realidad hondureña, a los propósitos y compromisos de la Universidad Nacional Autónoma de Honduras y la Universidad Pedagógica Nacional Francisco Morazán, en alianza con el Centro de Investigación y Promoción de los Derechos Humanos-CIPRODEH; así como a las intenciones de dar continuidad y/o sostenibilidad a las acciones y productos que se han venido desarrollando en el marco del Proyecto Asociativo Regional "Apoyo a la Educación, Capacitación e Investigación en Derechos Humanos en Centroamérica" con la cooperación del Gobierno de Finlandia.

El Manual de Derechos Humanos para Docentes de la U.P.N.F.M. (en adelante MDH-2009) cita una clasificación de los derechos humanos por el sujeto (individuales - colectivos, y agregan los derechos de los pueblos); otra clasificación por la naturaleza: civiles y políticos, económicos, sociales, y culturales (MDH-2009, Pág. 30). En la primera clasificación, entendemos que derechos de los pueblos deriva del derecho colectivo; o bien derechos de los pueblos y derechos colectivos pueden estar significando lo mismo. En la segunda clasificación, si nos guiamos por un criterio integral y concatenamos derechos humanos con desarrollo humano, al menos completaríamos la trilogía del desarrollo humano sostenible: económico, social, ambiente, agregando este último; más los derechos cívicos-políticos que ya están definidos; y ampliando los derechos culturales a derechos históricos, culturales y étnicos.

El marco de este Plan de Sostenibilidad de Iniciativas y Redes de Derechos Humanos en Honduras, con Visión Regional Centroamericana 2010-2015 (en adelante PSDH, 2010-2015), sin desentenderse de los derechos individuales, se potencian los derechos colectivos y derechos de los pueblos. Del primero es para enfocarse en el fin último como ser el bien común o de grupos organizados y no organizados. Para lo segundo, pueblo debe entenderse -en primer lugar- como la población general con énfasis en la más necesitada, en condición de pobreza y pobreza extrema o sin pleno goce de sus derechos civiles y políticos, y sin derecho (o excluido) del usufructo de los recursos naturales en su lugar de convivencia. La categoría pueblo también pudiera estar referida, en este contexto, al derecho de las comunidades, las localidades, las municipalidades, y a la construcción de una 
Vol. 4 $\mathrm{N}^{\circ} 1$ 2013

E\&A IIES

nueva ruralidad integral e incluyente. Más que en la falacia clásica del soberano, se enmarca en el enfoque social antropocéntrico. Interesa:

a. Definir unos ejes para la promoción de los derechos humanos de la juventud excluida de los procesos de desarrollo;

b. Develar las formas de discriminación múltiple a la mujer y estrategias de superación;

c. Denunciar la situación de pobreza infantil por cuatro causales, entre otras: niños pobres por deficiencia en la educación; niños pobres por insalubridad; niños pobres por ser trabajadores; niños pobres por carecer de la alimentación básica. (Por cierto que los niños son los que más sufren, numéricamente, de la violación de los derechos humanos elementales).

La noción de individualismo es herencia de la economía clásica de Adam Smith; que también se nutre de egoísmo y de competitividad: que juntando los elementos y trabajados al máximo en individualidad conducirían en su sumatoria al bien común por un efecto contingente denominado "derrame" (que incluso -proponen este mecanismo como la vía más acertada de resolver la pobreza). Para esta noción, si hay un común es la empresa y no la sociedad; y si hay un individuo, es aquel preocupado por la obtención de ganancia derivada de la propiedad privada sobre su medio de producción (en esta concepción no cabe la noción de solidaridad, convivencia, distribución, justicia; a las cuales las denominan como "nociones morales" o "juicios de valor" y hasta acientíficas). Actualmente hay una crítica abundante a la obsesión por la ganancia y al olvido del individuo, la familia, la comunidad, la gente, "el pueblo".

El Informe sobre Desarrollo Humano, Honduras 2008/2009: "De la exclusión social a la ciudadanía juvenil" (en adelante IDH 2008/2009) estructura una crítica a la individualización y prefiere la socialización. Con relación a la individualización acusa "...ha reestructurado y debilitado las instituciones claves de la estructura de las sociedades industriales clásicas, como el trabajo, la familia y la clase social...". "El Estado Nacional, la clase, la etnicidad y la familia tradicional están en declive” (IDH 2008/2009, Pág. 31).

La intención de potenciar los derechos colectivos, es por el rescate de la lógica del bien común, lo es porque este es un asunto de socialización, de cobertura para todos, y no de individualización, de privilegios u otras connotaciones degenerativas. Desde luego, hay una claridad de lo irrenunciable de los derechos y 
garantías individuales, pero las acciones del PSDH 2010-2015 van hacia la garantía de los derechos del bien común. También, lo es como una forma de rescatar los espacios tradicionales de socialización y co-responsabilizarlos: El Estado, la familia, la escuela, la iglesia, la comunidad, y sumamos a las ONGs y en especial a las Universidades. El IDH 2008/2009 apunta: "En una época caracterizada por la globalización económica y cultural, el impacto de las nuevas tecnologías de la información y la comunicación, y la crisis de las identidades políticas; los espacios de socialización tradicionales han ido perdiendo influencia y nuevos agentes de socialización han ido adquiriendo mayor relevancia: ejemplo, los medios de comunicación (IDH 2008/2009, Pág. 3)”.

Se reitera la potenciación al máximo de los derechos colectivos y el ligamento de esta idea con el bien común o con el bienestar y la concepción del desarrollo humano. Bienestar común es goce colectivo de los derechos más trascendentales. Queremos dejar la idea que igual que en economía, los derechos individuales son individuales, y la sumatoria no hace el colectivo ni el ejercicio de derechos del pueblo. Volviendo a Adam Smith (a quien se debe contrariar), planteó que la forma viable de llegar al bien común era a partir del esfuerzo individual (lo que ahora el léxico transforma en competitividad y productividad). Smith nos habla de manera matizada de un egoísmo sano que llevaría a maximizar los intereses privados, y que luego la suma de intereses privados constituye el Bien Común (Ver Malta, PDEL, Pág. 13). Wim Dierckxsens contraría y se apega a lo colectivo con lo siguiente: "El Bien Común consiste en el hecho de que las personas o los grupos que componen una sociedad tienen intereses que no pueden ser reducidos a la suma de intereses individuales". "La suma de intereses privados en conflicto sin regulación alguna, se aparta, mediante una mano invisible, del Bien Común" (Citado por Malta, PDEL, Pág. 14 y 16).

En otro punto relacionado, el enfoque o la naturaleza de derechos humanos asumida en el PSDH 2010-2015 se conforma de tres (3) dimensiones: 1 ra. La Política (incluye derechos civiles); 2da. Socio-Económica (incluye derechos históricos, culturales y étnicos); 3ra. Ambiental. La dimensión política tendrá su asidero práctico en la crisis política a partir de 28 de junio de 2009; la dimensión socioeconómica se justifica en la condición estructural de pobreza extrema de la mayoría de la población hondureña; y la dimensión ambiental se define por el cambio climático a nivel internacional, como por la necesidad de que las comunidades hondureñas se apropien de sus recursos locales. En el problema ambiental, las intervenciones estarían limitadas por dos excesos del ambiente: sequías e inundaciones (en parte, provocados por la destrucción de los bosques - 
Vol. 4

E\&A

IIES

talas y quemas indiscriminadas). Las sequías provocan hambre e inseguridad alimentaria y las inundaciones afectan directamente sobre todo a los pobres. Estas dimensiones engloban los siguientes enfoques: la democracia por la dimensión política; la seguridad económica (en vez de libertad económica) por la dimensión económica y social; el desarrollo humano sostenible por las dimensiones económica, social y ambiental.

\section{EPISTEMOLOGÍA DE LOS DERECHOS HUMANOS POR LA TOLERANCIA, LA INCLUSIÓNY EL ECODESARROLLO}

En lo que respecta al fundamento teórico, de forma general se tiene en cuenta la construcción teórica del Programa de las Naciones Unidas para el Desarrollo (PNUD) sobre derechos humanos, desarrollo humano y seguridad humana; en el aspecto práctico, son aleccionadores los resultados, impactos y sostenibilidad alcanzados por el Centro de Investigación y Promoción de los Derechos Humanos (CIPRODEH), en especial: en formación de redes étnicas, el derecho a la tierra y construcción de indicadores en desarrollo humano. Pero no es suficiente, en consecuencia, para la intervención en el tema de los derechos humanos, hace falta reunir una base conceptual más sólida y afrontar apropiadamente los déficits en términos de derechos humanos. Es aquí donde surge la ventana de oportunidades y el rol de las universidades en el problema del irrespeto de los mismos.

Para los fines de este PSDH 2010-2015, en lo político tendrá su fundamento epistemológico en John Gray, a su vez discípulo de John Locke (precursor de la teoría del equilibrio del Estado, antes de Rousseau y Montesquiu); en lo socioeconómico, en Bernardo Kliksberg, quien -en este momento- es el mejor acompañante de las teorías de Amartya Sen (premio Nobel en economía: precursor de la ética del desarrollo -juntos publicaron "Primero la Gente"); en lo ambiental, en Enrique Leff, quien es fundador de la disciplina de Economía Ambiental (El Eco desarrollo). La intervención de la UNAH, UPNFM y CIPRODEH, define su techo de búsqueda de la forma siguiente: en lo político, más tolerancia y reconocimiento del otro; en lo económico, más igualdad e inclusión; en lo ambiental, más apropiación de las comunidades de los recursos locales.

\subsection{Más tolerancia y reconocimiento del otro:}

John Gray desmiembra al liberalismo en dos filosofías desencontradas, ambas regidas por la tolerancia. Por un lado, la tolerancia es un instrumento de consenso racional ante la diversidad de modos de vida. Por otro lado, la tolerancia es una 
condición de paz entre los distintos modos de vida. En la primera filosofía, la diversidad de modos de vida se acepta por la convicción de que desaparecerán. En la segunda filosofía, la divergencia es síntoma de buena vida. Lo primero busca una convergencia última de valores. Lo segundo un ideal de modus vivendus. La primera concepción predomina. La segunda es la propuesta de John Gray o una filosofía liberal diferente.

Con esas dos caras del liberalismo y de la mano con la preocupación de los derechos humanos, las notas de Gray se comprimen de la siguiente manera (Gray, Pág. 123):

"La concepción liberal predominante de la tolerancia la concibe como un medio de llegar a una civilización universal. Si abandonamos esta concepción y aceptamos un mundo en el que coexisten muchos modos de vida y muchos regímenes, tendremos que repensar nuestras ideas sobre los derechos humanos y el gobierno democrático. Reacondicionaremos estos legados para adaptar a una filosofía liberal diferentes".

Ligeramente podríamos concluir: La tolerancia liberal es intolerante en ambas vías (a) Entendiéndome con el otro mediante un consenso a la fuerza; o bien (b) Una paz forzada por desentenderme del otro. Quedan dos caminos inútiles: imponer el consenso o aceptar las degeneraciones de otros modos de vida. Y vienen las primeras preguntas: ¿Cómo vivir juntos en una sociedad que alberga diferentes modos de vida? Esencialmente extra rico y extra pobre, y en medio los esforzados; ¿Cómo encontrar un modus vivendus armónico en un país tan plural? Que no sólo es nacional o liberal; liberal o conservador.

Hay cosas que el liberalismo no puede resolver; los irrespeto, los vejámenes, los pesares, la perplejidad de la pobreza y la precariedad de muchos derechos humanos no se puede esconder. Al liberalismo imperante, eso le genera un conflicto de valores, porque en su fundación fue anti- monárquico, anti-imperio, anti- feudal y exageradamente democrático; entonces, en vez de reconocer que hacen falta cambios de rumbos o signos de cambio, se enfrascan en dar explicaciones racionales a lo irracional:

Dice Gray (Pág. 49): “Desde Locke y Kant hasta Rawls y Hayek, toda una línea de pensadores liberales ha aceptado que los bienes vitales chocan entre sí y que no hay manera de resolver sus demandas opuestas sin pérdidas; pero esos pensadores han intentado establecer principios del bien y la justicia que se mantienen a 
Vol. 4

E\&A

IIES

distancia de estos conflictos. Si, sin embargo, las exigencias de justicia encarnan valores que son en sí mismos incompatibles e inconmensurables, esa versión del proyecto liberal queda encallada. Deberíamos adoptar una filosofía liberal cuyo ideal-guía no sea la quimera del consenso racional o una idea de desacuerdo razonable, sino el modus vivendi entre modos de vida que siempre serán diferentes".

Y abrimos interrogantes para incomodar a Gray y pensar si -¿hay oportunidad de construir tolerancia en nuestros espacios intolerantes? Y empezar a pensar qué tanto espacio avanza y ofrece Grey, cuando en el trasfondo de su propuesta hay un maquillar del liberalismo político; cuando podría estar avalando que no hay manera de resolver demandas opuestas; cuando desconcierta al imaginar que, los modos de vida siempre serán diferentes (seguiremos pensando el mundo rico y pobre). Como Gray lo hizo, debe plantearse un repensar de los derechos humanos y tener claridad de qué filosofía se desprenden. La otra opción es adoptar ciegamente lo convenido. ¿Será ingenuo decir que el legado de la Revolución Francesa, la Declaración de Independencia de los Estados Unidos y la misma Declaración Universal de los Derechos Humanos quedan un poco lejos de nuestras expectativas de goce de derechos humanos, si en ellas no se contiene nuestra condición de vida, nuestra problemática propia, nuestro anhelo único de paz, libertad, justicia, igualdad?. Ante esto, las traducciones homogéneas quedan grandes, y declaraciones de derechos que no son vinculantes ni obligatorias, todavía no son derecho. ¿Acaso hará falta convencer a los "dadores de derechos", que lo hagan de forma genuina para que los demás empiecen a gozarlos?

\subsection{Más igualdad e inclusión:}

La pobreza es un asunto de irrespeto de derechos humanos. Así se interpreta desde el abordaje de Bernardo Kliksberg en su libro "Hacia una Economía con Rostro Humano".

Uno de los primeros planteamientos a rescatar de Kliksberg es: "Hay tiempos de perplejidad ante el escándalo de la pobreza". Toma como punto de partida de sus análisis para América Latina las siguientes interrogantes: ¿Por qué un continente potencialmente tan rico genera un modo de vida tan oprimente para muchos? ¿Qué justificación tienen las desigualdades, tan acusadas en la región, que han llamado la atención internacional? ¿Cómo en una época de tantos avances tecnológicos, que muchas veces multiplican la capacidad de producir bienes y solucionar problemas, llega tan poco a la mayor parte de la población? La pobreza no es una abstracción estadística, se manifiesta día a día en la vida cotidiana. La mayor 
perplejidad es que la pobreza mata. En América Latina la pobreza se manifiesta entre otros aspectos en el plano más básico, la alimentación: las hambrunas. ¿Y cómo es posible que estos pobres sean invisibles? ¿Y seguirán creciendo? Esta es la gran incógnita. Lo más inmediato que hace Kliksberg es recurrir a: ética, solidaridad, cultura, valores, democracia, participación, capital humano, capital social.

\section{Causas del problema:}

La pobreza no solo es carencia de recursos económicos. Ésta es una de sus dimensiones centrales, pero hay otras de gran trascendencia. En un Informe del Banco Mundial, "Las voces de la pobreza", los pobres expresan tres opiniones básicas: Primero, opinan que están peor que antes y con más inseguridades. Segundo, no les preocupa sólo la falta de trabajo y de ingresos estables. Tercero, un aspecto central de su vivencia de la pobreza, que los afectan especialmente, son los atentados permanentes a su dignidad humana y el irrespeto a sus derechos humanos. En este aspecto, hay mucha discriminación, y nacen categorías como: los más pobres de los pobres, países pobres altamente endeudados, los niños de la calle, los descartables, los indeseables, los miserables, los viciosos de su propia miseria. El irrespeto a los derechos humanos como causal de pobreza se especifica mejor en los siguientes acápites:

a. Aguda desigualdad que la genera, la reproduce y la amplía: "Las 200 personas más ricas tenían, en 1999, 1.135.000 millones de dólares; mientras que, del otro lado, los 582 millones de habitantes de 49 países más pobres, sumaban un producto bruto total de sólo 146.000 millones".

b. Con relación al crecimiento, cabe analizar la calidad de éste. Las preguntas son: hacia dónde va el crecimiento, cuáles son las prioridades, a quién beneficia.

c. Ineficiencia de las instituciones gubernamentales y de desarrollo. Dichas instituciones no gozan de la credibilidad de los pobres, y más bien piden que se les fortalezcan sus instituciones de base. Sienten que al fortalecerse esas organizaciones de base y ellos mismos participar en ellas, comienzan a recuperar su dignidad.

d. Una fuente central de la pobreza es la carencia de poder de los pobres: Se plantea que los pobres, organizados, tendrán más influencia en los gobiernos 
Vol. 4

E\&A

IIES

locales; habrá que rendirles cuenta y podrán formar coaliciones con otros sectores de la sociedad civil para presionar por políticas más adecuadas.

En síntesis, la pobreza tiene esas múltiples dimensiones: No es sólo una cuestión de carencias económicas. Entraña una VIOLACIÓN DE DERECHOS HUMANOS en gran escala. Derechos como el acceso a la salud, a constituir una familia y tener estabilidad para ella, a la nutrición, a la educación, al trabajo, a la propia cultura, a ser escuchados, a participar.

\section{¿Cuál es la estrategia del rostro humano?}

Kliksberg busca una respuesta a ¿Cómo salir de la perplejidad? ¿Cómo recuperar una concepción válida de las causas de los graves problemas sociales de la región $\mathrm{y}$, a partir de ella, construir capacidad propositiva efectiva para encontrar soluciones? Según la percepción del rostro humano la pobreza no es una maldición inevitable. Es producto de decisiones políticas humanas. Enfrentarla requiere cambios en reglas de juego internacionales y en políticas nacionales.

Reglas del Juego Internacionales: a. Apertura real de mercados a los productos de los países en desarrollo. b. El alivio efectivo de la deuda externa. c. El aumento de la ayuda internacional.

\section{Políticas Nacionales:}

a. A nivel nacional urge, entre otros aspectos, crear empleos apoyando decididamente a la pequeña y la mediana empresa.

b. Democratizar el crédito.

c. Practicar políticas sociales agresivas.

d. Universalizar el acceso a la salud y a la educación de buena calidad.

e. Impulsar reformas fiscales de signo progresivo.

f. Empoderar a los pobres apoyando la creación y el fortalecimiento de sus propias organizaciones.

Con relación a una nueva estrategia de desarrollo, Kliksberg es crítico de la teoría económica convencional y detalla diez falacias de la misma:

1. La negación o la minimización de la pobreza: Muchas cifras se ajustan y desfiguran la realidad y magnitud del problema. 
2. La falacia de la paciencia: Hay que ajustarse el cinturón. Inadecuadamente se llega a reconocer que las penurias son parte del proceso de desarrollo.

3. Con el crecimiento no basta: El pensamiento económico ortodoxo lanza la idea desviada de que con el crecimiento es suficiente.

4. La desigualdad es un hecho de la naturaleza y no obstaculiza el desarrollo: Esto es falso. La desigualdad tiene que ver con políticas humanas e institucionales. También, erradamente, algunos economistas convencionales más extremos llegan aún más lejos, y plantean que esa acumulación de recursos en pocas manos favorecerá el desarrollo al crear mayores capacidades de inversión.

5. La desvalorización de la política social: Frente a exigencias de política social, algunos tomadores de política responden inadecuadamente, "la única política social es la política económica".

6. La maniqueización del Estado: El pensamiento económico convencional hace un sobreesfuerzo sistemático para deslegitimar la acción del Estado.

7. La incredulidad sobre las posibilidades de aporte de la sociedad civil: El énfasis del convencionalismo está volcado en los mercados, y procura opacar el papel de las organizaciones sociales.

8. La participación sí, pero no: Hay un discurso sobre la participación, pero aún no se generan espacios de participación auténtica.

9. La elusión ética: Esta es una variable olvidada.

10. No hay otra alternativa: Da la impresión de que nada se puede cambiar. Impera la desesperanza.

Se procura limitar las opciones y/o posibilidades del desarrollo. En tal sentido para Kliksberg siempre habrá alternativas. Imaginemos salidas:

a. Aprendamos que sí hay salida. Es necesario buscarla a través de la democracia, forjando amplias concertaciones nacionales que cambien un 
Vol. 4

E\&A

IIES

rumbo que no es ineluctable. ¿Seremos capaces de hacer honor al desafío: construir sociedades que posibiliten una vida digna para todos, que es la visión que se halla en las gestas libertarias de América, o el sufrimiento de millones continuará? (Kliksberg, 2002:11).

b. La siguiente reflexión de Félix Rohatyn (2000), Embajador de Estados Unidos en Francia, también figura una alternativa: "para sostener los beneficios (del actual sistema económico) en los Estados Unidos y globalmente, tenemos que convertir a los perdedores en ganadores. Si no lo hacemos, probablemente todos nosotros nos convertiremos también en perdedores".

c. Esto es como dice Hinkelammert: "El asesinato es un suicidio". La desesperanza es lo peor: Si sigue la desesperanza que pareciera natural, pero es una sensación construida, la desesperanza misma se constituye en una causa de la pobreza. Para Hinkelammert, "la cultura de la desesperanza es el heroísmo del suicidio colectivo": "En lo ideológico, las falsas democracias se fundan en la negación de cualquier alternativa, de la esperanza. Es una sociedad que sostiene que para ella no hay alternativa. Estabiliza las sociedades por la desesperación, a diferencia de las décadas de los cincuenta y los sesenta que estabilizaron por esperanzas (aunque muchas veces falsas)". Mediante una guerra psicológica se instaura la cultura de la desesperanza: la anomia. "Las organizaciones de clase o revolucionarias, los movimientos de cambio, la orientación hacia una nueva sociedad, surgieron de la cultura de la esperanza de los años cincuenta y sesenta. Ellos formularon la esperanza o la manipularon, sin embargo se basaron en ella. La destrucción casi general de los movimientos populares y del Estado de reforma (intervencionista) acabó con esta cultura, hizo que la cultura de la desesperanza lograra una gran fuerza de convicción sobre todo a partir de la crisis del socialismo en Europa oriental. Esta cultura se fundamenta en la tesis de que no hay alternativa. Únicamente se puede administrar un caos y una anomia, que son producidos de manera sistemática".

Finalmente: "Donde la cultura popular no se entrega sin más a la cultura de la desesperanza, para no ser una cultura de víctimas que se resisten a aceptar que la culpa la tienen ellos... Es una sobrevivencia de dignidad, no de poder. Es el último baluarte que se defiende antes de caer de la desesperanza en la desesperación". (Hinkelammert, 1995: 123, 128 y 130). Con esto, lo que sucede es que al 
arrebatarle a la gente todos sus derechos humanos -y sin instancias que lo protejan- y sin representación que valga, a esto sigue la desesperanza. Y la desesperanza es inercia para la permanente condición de pobreza. Entonces, apostarle al crecimiento económico, al desarrollo humano, al combate a la pobreza, procurar seguridad humana y cumplimiento de los derechos humanos, todo ello pasa ineludiblemente por rescatar la dignidad de la gente. El precepto de Theodore Shultz de "Invirtiendo en la Gente", como el de Amartya Sen de "Primero la Gente", debemos cambiarlo por rescatando a la gente.

\subsection{Saber ambiental y usufructo comunitario:}

Enrique Leff, 1975, es uno de los más elocuentes críticos del irracional daño ambiental actual. Sus aportes han contribuido a la estructuración de una nueva disciplina económica, y es la Economía Ambiental (Ecodesarrollo). Es el hombre del "saber ambiental". A continuación un análisis basado en sus principales ponencias:

Se dice que desde los años setenta la naturaleza ya no aguanta la locura reproductiva de un mundo sin límites que ha conquistado totalmente a la naturaleza, para ganar en el corto plazo o ganancia de pocos (que no es la comunidad) y pérdida al final. Con la naturaleza negada por la lógica irracional del crecimiento económico, sencillamente se pierden las bases del desarrollo y de ahí surge "el principio de sustentabilidad". Pasan dos cosas: la sustentabilidad no surgió por conciencia, por convencimiento, sino por una necesidad ante la crisis ambiental; derivado, la sustentabilidad es todavía un principio normativo, que quiere decir que se encuadra en lo que debe ser, lo incursionan en el ámbito de los juicios de valor. Sí se reconoce el problema, pero no se obliga una solución: como muestra, el Protocolo de Kyoto no está firmado. Esto quiere decir que al descuidar a la naturaleza como soporte, y verla como campo de oportunidades para la acumulación, lo que se pone en riesgo es la sobrevivencia sobretodo de las comunidades pobres, y esto es un asunto directo de DERECHOS HUMANOS. Si los derechos humanos son concurrentes a la paz, la justicia, la convivencia, respeto de la dignidad y la humanidad, salvamento de la civilización; para Leff el principio de la sostenibilidad sería el garante de tales derechos:

"El principio de sustentabilidad emerge en el contexto de la globalización como la marca de un límite y el signo que orienta el proceso civilizatorio de la humanidad". 
Vol. 4

E\&A

IIES

El desarrollo sostenible es una preocupación quizá más abordada que los derechos humanos. Será porque se pone en riesgo la humanidad en su conjunto; en cambio en derechos humanos hablamos de los riesgos de los pueblos, de los colectivos y de los individuos. Es hora de dar cabida a la generación de los derechos ambientales, en este momento justo de la crisis ambiental - del calentamiento global, y porque aquello que no está depredado, de todas formas, ya no pertenece a las comunidades. Se descubre acá otro causal de pobreza, que no es la trillada falta de medios de producción; se trata de la ausencia de posesiones sobre la naturaleza y por lo tanto, ningún usufructo deriva de las mismas.

Leff configura un concepto de ambiente desde el desarrollo humano (ecodesarrollo), que primero reintegre los valores y potencialidades de la naturaleza; eso quiere decir que a la naturaleza no se le ve como soporte para la sobrevivencia, en consecuencia, todo daño a la naturaleza repercute en un irrespeto de los derechos humanos. Segundo, acusa a los anti-naturaleza de las externalidades sociales. Eso debe entenderse como que el daño ambiental que provocan los privados sigue pagándose vía costo social, lo cual se constituye en otro irrespeto a los derechos humanos y a la inteligencia del hombre. Tercero, se advierte que los saberes están subyugados; significa que deliberadamente no se reconoce el conocimiento local, como otra forma de negación e irrespeto de los derechos humanos (se anulan las alternativas de desarrollo endógeno local). Cuarto, se impone una racionalidad simplificadora, unidimensional y fraccionadora; y esto es lo peor, porque significa el aniquilamiento de las personas. ¿Qué más prueba de irrespeto de los derechos humanos, siendo que las personas se van cosificando y las cosas (el mercado) se van personalizando?

El verdadero concepto de desarrollo abarca cosas esenciales, que no solo se reducen a la creación de una especie de materialización de la vida, donde cada persona es reducida simplemente a la condición de consumidor, un elector, o productor. De modo que toda la dimensión humana se ve aplastada y/o eliminada por el ser económico-reductivo. Siendo así, hay un reduccionismo, sobre la base de ver el crecimiento económico como lo que no es: como si fuera sinónimo del desarrollo. Tal confusión obliga a tener una visión justa y correcta del contenido del desarrollo. (Malta, Revista POSCAE, 1999: Págs. 84 y 85).

En medio de esta tradición ignorante de utilizar inapropiadamente la naturaleza, lo que queda por salida es el "saber ambiental" que se circunscribe a dos ámbitos: las universidades y las comunidades. Deben potenciarse en serio las disciplinas de la "educación ambiental" y la "economía ambiental". Enrique Leff y Jefrey y Sach 
son contundentes:

"Es necesario fundar NUEVOS MODOS DE PRODUCCIÓN y estilos de vida en las condiciones y potencialidades ecológicas de cada región, así como en la diversidad étnica y la autoconfianza de las poblaciones para la gestión participativa de los recursos".

Sucede que pese a todas las adjetivaciones de principios de sustentabilidad, crecimiento sostenible, desarrollo sostenible, ecodesarrollo, crecimiento económico y conservación de la naturaleza, explotación - conservación, persiste la apropiación de unos y la exclusión de otros al derecho de la naturaleza que se hace manifiesto en: explotación económica de la naturaleza, la degradación ambiental, la desigual distribución social de los costos ecológicos y la marginación social. Se apela a la Conferencia de las Naciones Unidas sobre el Medio Ambiente Humano (Estocolmo 1972); Comisión Mundial sobre Medio Ambiente y Desarrollo (1984); a su Informe Bruntland de 1988; Conferencia de las Naciones Unidas sobre Medio Ambiente y Desarrollo (Río de Janeiro 1992); y suAgenda 21.

De todo lo actuado en materia de ambiente resultan contrastes. En la aproximación, en el aclarar estos contrastes radica el mayor aporte de las instituciones de investigación, formación e incidencia política:

a. Por un lado observamos el crecimiento económico, por el otro anhelamos la conservación de la naturaleza;

b. Por un lado se va divulgando la concepción del desarrollo sostenible, por el otro se va vulgarizando, diluyendo y pervirtiendo el concepto en la internalización de costos;

c. Por un lado la fuerza de las empresas transnacionales apropiándose de la naturaleza, por el otro lado los grupos indígenas y campesinos defendiendo su derecho histórico de apropiación;

d. Por un lado el ecodesarrollo instala bases morales y productivas para el modo de producción, por el otro lado el neoliberalismo ambiental destruye las formas de vida;

e. Por un lado se niega la causa de la crisis ambiental, por el otro resultará en la profundización del irrespeto a los "derechos humanos ambientales".

Cabe anotar que los derechos ambientales antes de ser reivindicativos son naturales; le corresponden por derecho al individuo, colectivos y pueblos. Veamos 
Vol. 4

E\&A

IIES

las siguientes expresiones de reforzamiento:

\section{Expresión 1:}

NO somos aves para vivir del aire.

NO somos peces para vivir del agua.

Somos hombres para vivir de la tierra.

\section{Bernardino Díaz Ochoa}

(Campesino, precursor de la reforma agraria nicaragüense.)

\section{Expresión 2:}

Cada parcela de esta tierra es sagrada para mi pueblo. Somos parte de la tierra y ella es parte de nosotros. Todo lo que le ocurre a la tierra les ocurrirá a los hijos de la tierra. El hombre no tejió la trama de la vida: él es sólo un hilo.

(Respuesta resumida del Jefe Seatle en 1854 al Gran Jefe Blanco de Washington que pretendía comprar las tierras de los indios Piel Rojas).

En fin, la razón tecnológica y la razón económica -que impera en nuestros paíseshan terminado en la sinrazón. Han provocado una deuda ecológica, deuda financiera, y deuda de la razón que hay que saldársela a los campesinos, a las etnias, a las comunidades rurales, a las familias y los pequeños productores. No hacerlo es validar el irrespeto de los derechos humanos ambientales. Ahora bien, siendo que el Informe Bruntland definió al desarrollo sostenible como un proceso que permite satisfacer las necesidades de la población actual sin comprometer la capacidad de atender a las generaciones futuras; en consecuencia, los derechos humanos ambientales trascienden hasta el aseguramiento de los derechos de las generaciones futuras.

\section{EN BUSCA DE NUESTRA GENERACIÓN DE DERECHOS HUMANOS}

La literatura convencional también cita otra categoría de derechos humanos por el momento de su reconocimiento legal: son las llamadas Generaciones de los Derechos Humanos (y es precisamente en este punto donde se le ha dado un rol marginal a los derechos ambientales, mismos que se exige su reconocimiento según el acápite antes desarrollado "saber ambiental y usufructo comunitario"). 


\subsection{Las generaciones históricas de los derechos humanos:}

La primera generación, constituye los derechos políticos (civiles, políticos e individuales). Deriva de las concepciones filosóficas de la ilustración, el iluminismo, la luz, el conocimiento, y retoma como emblema práctico la Revolución Francesa y la Independencia de los Estados Unidos. Su fin primario y último es la democracia. Dar fin a las monarquías, caudillismos y tiranías. Se puede decir que los países desarrollados han consolidado el goce de este derecho, pero los países en proceso de desarrollo tienen democracias jóvenes; han padecido una historia política de golpes de Estado, dictaduras, gobiernos de seguridad nacional y democracia de paralelas históricas (liberales y conservadoras) que se heredaron desde la Colonia y que no dan apertura real al pluralismo político.

La segunda generación, se centra prioritariamente en los derechos socioeconómicos (culturales y para el colectivo). A través de este precepto se pone en evidencia las diferencias y/o desigualdades económicas entre distintos grupos sociales y entre países (principalmente los del norte y los del sur y ahora hay una tesis que indica que cada país tiene su propio Norte y Sur). Históricamente, se circunscriben a la Revolución Rusa y Revolución Mexicana; en tanto hacen trascender la noción de derechos individuales a derechos colectivos. Detrás estaba la explicación política (y no la necesidad económica) de contrariarse entre los sistemas imperantes (capitalismo y socialismo): uno proponiendo la propiedad privada (individual) sobre los medios de producción; y la otra concepción apegada a la propiedad común sobre los medios de producción.

En medio de esa discusión, se fija más la idea del pueblo; de la necesidad de promover los derechos de los pueblos. En el Informe sobre Desarrollo Humano, Honduras, 2006, el PNUD ha denunciado el déficit de los derechos socio económicos haciendo un planteamiento novedoso de "Hacia la expansión de ciudadanía", que sencillamente significaba que de nada valían los avances democráticos (en el cumplimiento de derechos políticos) si a su vez la mayoría de la población estaba en condiciones de pobreza o pobreza extrema. A la fecha (y desde el 2010), se concluye que las instancias de derechos humanos del país (el Estado mismo, universidades y otros) hicieron un "reenfoque" hacia fijar la mirada en la generación de derechos económicos, sociales y culturales, ligando de forma directa a los derechos humanos con la noción de desarrollo humano; pero también ello implicó un descuido de profundizar los derechos políticos en el entendido de que la democracia hondureña era guiada por su propia inercia hacia una construcción democrática. Después de la crisis política hondureña de 2009 y 
Vol. 4

E\&A

IIES

las consecuencias subsiguientes, las reflexiones son diferentes y urge retomar las preocupaciones fundamentales por el goce de derechos políticos, y por tanto las instituciones están en un nuevo proceso de replanteamiento en la atención a los derechos humanos, desde un enfoque integral y no siguiendo la lógica parcial e histórica de las generaciones de derechos humanos.

La democracia hay que seguirla inculcando, la paz, el consenso no forzado; pero también hay que resolver la pobreza, la desigualdad, la injusticia social. Pareciera que la noción de generación de derechos humanos habla de lo que los pueblos desarrollados han conquistado, pero a su vez del largo camino que les queda a las democracias jóvenes y pobres. La generación tradicional de derechos humanos habla de la necesidad de ver una imagen en lo que otros países han logrado, pero a veces, no contextualizada a la realidad nacional; por ello urge la conciencia y solidaridad internacional aparejado con la conciencia y compromiso nacional.

La tercera generación. Si la primera generación aboga por la libertad, la segunda por el derecho de los pueblos a gozar de la prosperidad, la tercera es la generación de la paz. Precisamente surge en el marco de la Segunda Guerra Mundial, por un nuevo orden internacional de paz: refiere al derecho de los pueblos y la solidaridad internacional. La lección que se retoma en este punto es que el logro de los derechos humanos no es responsabilidad de cada nación, sino del concurso del mundo entero, en una estrategia obligada de solidaridad y concordia internacional. Cabe destacar que Centroamérica en la década de los 80 s. fue zona de turbulencias sociales y políticas en medio de la guerra fría internacional, que finalmente culminó con los Acuerdos de Paz de Esquipulas y con el compromiso de ver una región unida y dispuesta a asumir los retos del mundo globalizado de forma regional. Los últimos hechos concurrentes de la región han sido, en el 2009, la crisis política de Honduras, y en el 2010, el Acuerdo de Asociación con la Unión Europea; en el primero ha habido desunión pacífica, en el segundo ha habido unión forzada. Queda la extraña sensación de que lo económico es imprescindible y no se puede interrumpir, pero lo político puede esperar. Y en este trasfondo están los retos aún vigentes de la región centroamericana y de los países con relación a los derechos de tercera generación: ocho universidades de la región centroamericana así lo están entendiendo y planteando a través de la Red Centroamericana Inter Universitaria para la Educación, la Capacitación y la Investigación en Derechos Humanos, con un rol protagónico de la UNAH y UPNFM. Acompañarán esta iniciativa (es lo que se espera y depende de la gestión apropiada de la Red): Universidad de San Carlos de Guatemala; Universidad de la Salle, Costa Rica; Universidad Rafael Landívar, Guatemala; Universidad de El Salvador; 
Universidad de Costa Rica; Universidad Politécnica de Nicaragua.

Resumiendo las tres generaciones, serían las muestras de un mundo moderno y solidario, que no está obligado a definirse vía el número de máquinas, los avances tecnológicos e informáticos: Se requiere ese mundo de libertad, paz y derechos de los pueblos. Las universidades están obligadas a formar ciudadanos, generar debate y soluciones apropiadas a estos temas en un ambiente de concordia, con criterios científicos, técnicos y con el punto de vista de la gente: es urgente potenciar la relación "Universidad-Sociedad Civil".

\subsection{La lucha contra la pobreza y la exclusión social define nuestra generación de derechos humanos:}

En vez de seguir la idea de generaciones de derechos humanos, este PSDH 2010 2015 se rige por las características de los derechos humanos reconocidas universalmente: universales, indivisibles, integrales, interdependientes, complementarios, relativos, irrenunciables, imprescriptibles, inalienables e inviolables (MDH - 2009, Pág. 28). Hacemos referencia a "nuestra generación de derechos humanos", a aquella que englobe a un grupo de derechos más contextualizados a la realidad de países pobres como Honduras.

Se fija la opinión de que el fin de la pobreza extrema, la reducción de la pobreza, el sentido de humanidad y dignidad en el tratamiento de las penurias de la gente, serían muestras evidentes del goce de los derechos humanos. Se trataría de una reivindicación grande en términos de derechos humanos para países como los latinoamericanos, los centroamericanos, particularmente Honduras. El Informe (mundial) del PNUD sobre la Pobreza (1998), "Superar la Pobreza Humana" es contundente en afirmar que:

"La dimensión de la pobreza humana al final del siglo XX es una afrenta a la dignidad humana" y por tanto es una muestra del no cumplimiento de los derechos humanos.

Pese a ser el fin del Siglo XX y principios del Siglo XXI, el período más productivo $\mathrm{y}$ de generación de riqueza de la historia económica; los pobres han proliferado. En consecuencia, se cumple la diatriba que nunca la entienden los liberales del mercado "el crecimiento económico es necesario, pero no suficiente". En la misma dimensión, James Gustave Speth, Administrador PNUD (1998), responde a la pregunta ¿Cómo se ha combatido la pobreza? “...más de lo que se cree 
Vol. 4

E\&A

IIES

normalmente, pero muchos menos de lo suficiente".

En la amplia revisión bibliográfica realizada, se ubica en Speth el origen genuino o el encuentro histórico de "nuestra generación de derechos humanos" al categorizar la pobreza en el andamiaje directo de los derechos humanos. Dice Speth: "Han transcurrido cincuenta años desde que se proclamó la Declaración Universal de los Derechos Humanos, y todavía un tercio de la población de los países en desarrollo está esclavizado por una pobreza tan completa que les priva de los derechos humanos fundamentales". Y sería inapropiado ubicar a la pobreza apenas en la dimensión económica, social y cultural, porque también es un problema de falta de voluntad política, y de no permisibilidad para el usufructo de los recursos naturales locales, mismos que les pertenecen a las comunidades "empobrecidas".

Pero no todo es contrario. Reconforta saber que por primera vez en la historia de los derechos humanos, el mundo trabaja por una generación de derechos humanos a favor de los pobres. El Informe Anual (mundial) 2009 del PNUD "Cumplir nuestro compromiso con el desarrollo" analiza la crisis financiera mundial (punto crítico - septiembre de 2008), no desde los flujos de financiamiento para la recuperación financiera, pero sí desde los flujos contingentes de dinero para que los pobres no salgan afectados en la crisis: divide a los pobres entre un grupo que se ha beneficiado del crecimiento económico de la última década, y otro que no ha recibido beneficio alguno. Al PNUD le interesa no observar retrocesos en el primer grupo y atención inmediata y de emergencia para el segundo.

Más allá de la crisis financiera, al Secretario General de las Naciones Unidas, Ban Ki-moon, le preocupa una probable detención o reversión en el progreso de los Objetivos de Desarrollo del Milenio (ODMs). Bajo la influencia del Secretario General se celebró en abril de 2009, la Cumbre del Grupo de los 20, en Londres. De ahí resultó el compromiso de seguir apoyando los ODM, dotando de más recursos financieros al FMI y Banco Mundial, para disponerlos a la protección social, seguridad alimentaria y cambio climático. El argumento sencillo y contundente de Ban Ki-moon es el siguiente:

“...garantizar que la asistencia llegue a los países más pobres será fundamental a medida que la crisis económica se convierta en una crisis del desarrollo y la seguridad humana". 
La pobreza es un efecto palpable de la permanente violación de los derechos humanos, porque niega la paz, la libertad y la dignidad humana. Kofi Annan, Ex Secretario de la ONU, nos brinda un concepto de pobreza lejos del planteamiento excluyente Malthusiano; y denuncia a quienes privan a los pobres del desarrollo, a quienes los empobrecen: "La pobreza es la forma más extendida de negación de las oportunidades y la capacidad de elección de las personas".

Para reforzar más la noción de un tratamiento verdaderamente genuino en los derechos humanos de los pobres o derechos humanos de los pueblos, se agrega lo que expresaron Helen Clark y Ad Melkert, Administradora del PNUD y Administrador Asociado respectivamente (2009): Clark afirma “...la comunidad internacional debe cumplir sus compromisos con los pobres. Este no es el momento de reducir la asistencia para el desarrollo, especialmente porque los más afectados no son los responsables de la crisis". Melkert por su lado afirma "Las preocupaciones de los ricos (ejemplo: la crisis financiera mundial) no deben convertirse en la penuria de los pobres". El giro hacia fijar la mirada en los derechos humanos de los pobres está dado: La misión original del PNUD era prestar asistencia y apoyo técnico para promover el desarrollo económico y social de los países en desarrollo. Actualmente el PNUD promueve políticas a favor de los pobres en la búsqueda del desarrollo humano.

\subsection{Derecho al Desarrollo y el Derecho Esencial a la Vida}

Sin cumplimiento de derechos humanos no hay posibilidad de desarrollo humano, y el derecho elemental a la vida se pone en riesgo: también la paz, la libertad y el ejercicio de solidaridad. Aunado a este criterio, el 2do. Informe de ODMs Honduras (en adelante IODMs2) plantea que "sin desarrollo social, el desarrollo económico se hace esquivo y difícil". De esta forma se liga a los ODMs con el desarrollo económico y social: Los ODMs son la base del desarrollo. El punto de convergencia de derechos humanos, desarrollo humano y seguridad humana es el combate a la pobreza. El mismo IODMs2 exige un cumplimiento base de:

a. Acceso a educación de calidad

b. Población saludable

c. Cultura de sostenibilidad ambiental

d. Identidad de los pueblos, para construir la patria de Morazán, Cabañas, Herrera y Valle. 
Vol. 4

E\&A

IIES

En la misma línea, se reconoce un rezago paralelo, tanto en el desarrollo social como en la construcción y reconstrucción de identidad nacional. Un detalle importante del IODMs2, es que reitera la necesidad de que el mundo académico se responsabilice, que sean parte del ejercicio compartido del desarrollo del milenio que está orientado a "desarrollo equitativo y solidario, de ampliación de las capacidades y oportunidades para todos". Se destaca la necesidad de la investigación y el debate sobre los grandes problemas y desafíos del desarrollo económico y social, así como la necesidad de alianzas intersectoriales (como por ejemplo, vinculación universidad - sociedad civil): "el concepto de responsabilidad compartida se basa en la idea de la solidaridad y en la certeza de que estableciendo relaciones de reciprocidad y compromiso para resolver situaciones que nos afectan socialmente, todos salimos ganando".

Tanto las ONGs como la Organización de las Naciones Unidas son coincidentes en el tratamiento de la pobreza como un problema de derechos humanos. Las ONGs relacionan a la pobreza como la violación más extendida de los derechos humanos. El PNUD plantea que la liberación de la pobreza es un derecho humano inalienable e irrenunciable. También el PNUD en toda su problemática general y de la pobreza en particular hace saber que todos son componentes importantes del derecho al desarrollo.

EI Derecho Esencial a la Vida: Es necesario aclarar que el derecho preeminente es la vida, por encima de los derechos civiles-políticos; derechos económicos, sociales y culturales; y ambientales. Estos derechos solo son importantes, en tanto ayudan a conservar la vida, la integridad y la dignidad humana. En otro punto, es necesario ver la "urgencia" de atender con prioridad a los derechos humanos, pero no implica establecer la noción de derechos humanos de "emergencia". En estos términos, "emergencia" quiere decir, esperar las hambrunas o la crisis alimentaria, los desastres de un huracán o los efectos del cambio climático, la crisis financiera o la crisis petrolera, u otras crisis para posteriormente reaccionar. En cambio, urgencia es la necesidad de una política que defina un actuar permanente y sistemático por la defensa de los derechos humanos, la defensa de la vida y la dignidad. Es más, las urgencias por los derechos humanos es un ejercicio permanente de renovación y/o profundización de los propósitos. Refuerza este pensamiento Helen Clark, Administradora del PNUD (2009) y Ex Primera Ministra de Nueva Zelandia:

“Ahora, ante una grave recesión económica mundial, la misión del PNUD adquiere una urgencia renovada. Se corre un serio peligro de que se reviertan los logros en materia de desarrollo alcanzados tras mucho 
esfuerzo. Además de los efectos del aumento del precio de los alimentos y el cambio climático, deberemos superar muchos obstáculos si hemos de alcanzar los Objetivos de Desarrollo del Milenio en 2015".

No hay duda que en los países pobres como Honduras lo que más se violenta es el derecho a la vida, derecho a tener oportunidades de trascendencia: La inclusión es un derecho a reivindicar. Ahora bien, el derecho a la vida se logra con inclusión: promoción del crecimiento inclusivo, la igualdad entre los géneros, reconociendo las legítimas diferencias y el logro de los ODMs; fomento de la globalización inclusiva; fomento de la participación inclusiva. En este ámbito, anotamos enseguida el concepto de derechos humanos, desarrollo humano y compromiso por la vida, como elementos inseparables en los que no importa redundar e insistir:

Derechos Humanos: Basado en el MDH-2009, el concepto hace referencia al sentido de la dignidad humana que es una condición o cualidad moral inherente a todo ser humano sin ningún tipo de limitaciones; sean estas económicas, físicas, culturales, raciales, sexuales, etc. Los tres ejes fundamentales son la dignidad, libertad e igualdad, y para efectos prácticos, el cumplimiento o la reivindicación de los derechos humanos tienen en cuenta el valor humano; define normas que regulen, promuevan y defiendan; y también como acción, la convivencia humana es expresión de ejercicio y gozo libre de derechos humanos.

Desarrollo Humano: Según el Informe Anual 2009 - PNUD, el desarrollo humano es un proceso de aumento de las opciones de las personas y el fomento de las libertades y capacidades humanas (todo lo que las personas pueden ser y hacer).

Compromiso por el Desarrollo: En fin, los resultados del desarrollo giran alrededor del mejoramiento real de la vida de las personas. Un buen ejemplo en la región ha sido el Programa de Desarrollo para Desplazados, Refugiados y Repatriados en Centroamérica, cuyo objetivo ha sido "reanudar una nueva vida a centenares de miles de personas indígenas, desplazadas por represiones violentas y guerras civiles".

El mismo Informe 2009 - PNUD, exige un compromiso con aquellos a quienes se les han conculcado sus derechos. La orden del día es la siguiente: "Vivir una vida larga y saludable, tener acceso a los conocimientos y un nivel de vida digno, y participar en la vida de sus comunidades y en las decisiones que afectan sus vidas". 
Vol. 4 $\mathrm{N}^{\circ} 1$ 2013

E\&A

IIES

24

\section{OPINIONES CONCLUYENTES}

Para cerrar este artículo, se vierten algunas opiniones concluyentes:

- La condición de pobreza y de pobreza extrema es una muestra inobjetable de violación de los derechos humanos.

- El derecho fundamental es la vida. Transfigurado a nuestra realidad de pobreza, penuria, vulnerabilidad e inculcación de derechos, el derecho fundamental es la calidad de vida.

- Somos tomadores de derechos, no decisores de derecho. Es necesario enunciar y decidir de forma legítima qué derechos seguir con más atención y ampliar el espectro de los mismos.

- Los derechos se vienen librando vía reivindicación o en medio de conflictos. Es necesario tener en cuenta la historia nacional de Honduras y no solamente lo que se ha venido definiendo según el entorno internacional.

- La definición de los derechos humanos no ha estado exenta del debate y la discusión entre capitalismo - socialismo.

- Los derechos humanos son una conjunción de principios elementales para el respeto de la vida, la persona y la convivencia armónica. Tanto los derechos políticos, económicos, sociales y ambientales, han estado desde siempre como derechos necesitantes (intrínsecos) y no apenas unas necesidades que van surgiendo de generación en generación. Lo que sucede es que políticamente, y según las coyunturas mundiales, se van reconociendo y asumiendo compromisos por los estados.

- Debe exigirse el rompimiento de la dualidad en el cumplimiento de los derechos humanos; siendo que los mismos deben ser vinculantes y exigidos tanto en los países desarrollados como en los países pobres.

\section{BIBLIOGRAFÍA}

Cámara, Gabriel, 2008. Otra Educación Básica es Posible. México, Editorial Siglo XXI.

Gray, John, 2001. Las dos caras del liberalismo: Una nueva interpretación de la tolerancia liberal (Título original: Two faces of Liberalism, 2000). España, Paidos, Estado y Sociedad. 
Kliksberg, Gerardo, 2011. Sus obras más reciente son el best seller internacional "Primero la gente" (19 ediciones), escrita con el premio Nobel de Economía Amartya Sen.2 y "Escándalos éticos", declarado de interés cultural por la Legislatura de la Ciudad de Buenos Aires (2011, sexta edición).

Leff, E., 1975. "Hacia un proyecto de eco desarrollo", en Comercio Exterior, vol. 25, núm. 1, México, pp. 84-92.

Malta, Joseph, 2000. Atacar la Pobreza Infantil Hondureña: Niñez, Pobreza y Deuda Externa. Tegucigalpa, COIPRODEN-FOSDEH.

Malta, Joseph, 2008. Economía para la Reducción de la Pobreza: Modelo de Desarrollo de Pequeña Producción y Cohesión Social. Tegucigalpa, Honduras, Ideas Litográficas.

Malta, Joseph, 2011. Plan de Transformación Social del Instituto Nicaragüense de Tecnología Agropecuaria - INTA: 2008-2015. Informe de tesis para obtener el grado de Máster en Economía Agrícola con Orientación en Agroindustria. Managua, UNAN-FFCCEE-DES.

Malta, Joseph, 2007. Principios de Promoción del Desarrollo Económico Local. Tegucigalpa, Ideas Litográficas. Asociación de Municipios de Honduras (AMHON). Comisión Cristiana para el Desarrollo (CCD). Proyecto de Bosques y Productividad Rural (PBPR-SAG).

ONU, 2007. Objetivos de Desarrollo del Milenio, Honduras 2007. Segundo Informe de País. El logro de los ODMs: una responsabilidad compartida. San José, Costa Rica, Litografía e Imprenta Lil, S.A.

PNUD, 2009. Informe Anual 2009. Cumplir nuestro compromiso por el desarrollo. Tegucigalpa, Honduras.

PNUD, 2009. Informe sobre Desarrollo Humano Honduras 2008/2009. De la Exclusión Social a la Ciudadanía Juvenil. Tegucigalpa, Honduras.

PNUD, 2006. Informe sobre Desarrollo Humano, Honduras. Hacia la expansión de ciudadanía. Tegucigalpa, Honduras.

PNUD. 1998. Programa de las Naciones Unidas para el Desarrollo. Informe del 
Vol. 4

E\&A

IIES

PNUD sobre la Pobreza 1998. Superar la Pobreza Humana. Impreso en Estados Unidos.

POSCAE, 1999. Postgrado Centroamericano en Economía y Desarrollo. Revista Centroamericana de Economía. Artículo de Joseph Malta: Insumos para el Desarrollo. II Época, Año 5, No. 55 y 56. Universidad Nacional Autónoma de Honduras.

Restrepo Rivera, Jairo y Pinheiro, Sebastiao, 2010. Agricultura Orgánica: Harina de rocas y la salud del suelo al alcance de todos. Brasil - Colombia - México, Primera Edición, Juquira Candirú Satyagraha. Tegucigalpa, Honduras, Segunda Edición, Producido por PROGRESO, GDF-C.A., Carmina Editores, Impreso en los Talleres Gráficos de Carmina Editores.

Salgado, Ramón, Compilador, 2010. Crisis Institucional y Golpe de Estado en Honduras. (1) Artículo de Fernando Mires: La Nueva Política Exterior de los Estados Unidos hacia América Latina. (2) Diálogo Guaymuras. Acuerdo Tegucigalpa - San José. (3) Acuerdo para la Reconciliación Nacional y el Fortalecimiento de la Democracia. Tegucigalpa, UPNFM.

UNAH, Comisión de Transición, 2008. Informe de Gestión de la Comisión de Transición Universitaria. Anexo III: Plan General para la Reforma Integral de la UNAH e Informes Anuales de la Comisión de Transición Universitaria. Ciudad Universitaria "José Trinidad Reyes".

UPNFM, Universidad Pedagógica Nacional Francisco Morazán. Vicerrectoría de Investigación y Postgrado. Dirección de Postgrado, 2009. Manual de Derechos Humanos para Docentes. Tegucigalpa, Ideas Litográficas, Primera Edición.

UPNFM, Rectoría, 2008. Plan Estratégico 2008-2014. Tegucigalpa.

Zuloaga, Patricia Palacios, 2005. Las Convenciones Internacionales de Derechos Humanos y Perspectiva de Género. LOM Ediciones, Primera Edición. 


\section{OTROS MATERIALES:}

- Carta de Entendimiento de la Red Centroamericana Universitaria para la Promoción de los Derechos Humanos.

- Discurso del Presidente Allan García como anfitrión de la 40 Asamblea General de las Naciones Unidas en Perú. Junio 2010.

- Discurso del Secretario General de las Organización de Estados Americanos, José Miguel Insulza, en la 40 Asamblea General de las Naciones Unidas en Perú. Junio 2010.

- Leff, Enrique. Texto: "Globalización, Ambiente y Sustentabilidad del Desarrollo".

- Matriz POA2010 del Proyecto Asociativo Regional en Derechos Humanos.

- Pacto Internacional sobre los Derechos Económicos y Sociales (Pacto DESC).

- Posada, Carmen. Derechos Humanos y Género. Consultora en Género, Derechos Humanos, Salud y Derechos Sexuales y Reproductivos. Directora de CERFAMI - Centro de Recursos Integrales para la Familia.

- Programa CNN, Junio 2010. Aristegui. Sobre el rompimiento de la Comisión Internacional contra la Impunidad en Guatemala (CICIG). 